\title{
Performance of Boron-Carbide as Radiation Shielding
}

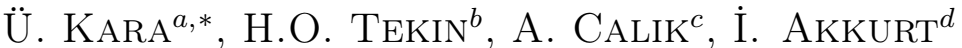 \\ ${ }^{a}$ Suleyman Demirel University, Vocational School of Healt Services, Isparta, Turkey \\ ${ }^{b}$ Usküdar University, Vocational School of Health Services, Istanbul, Turkey \\ ${ }^{c}$ Suleyman Demirel University, Manufacturing Department, Isparta, Turkey \\ ${ }^{d}$ Suleyman Demirel University, Physics Department, Isparta, Turkey
}

\begin{abstract}
Radiation is widely used many fields, especially in medical science. The shielding is the basic method of protection against unnecessary influence of radiation. One of the tools most commonly used in nuclear medicine is vial pig container. Usually lead is used as shielding material in vial pigs to cover radiation source, such as $\mathrm{Tc}^{99 \mathrm{~m}}$ which is the most widely used radiopharmaceutical in nuclear medicine. In this study boron carbide has been tested as an substitute of lead in vial pig. The measurement has been performed with the Geiger-Müller counter and the personal combined radiation detectors.
\end{abstract}

DOI: 10.12693/APhysPolA.128.B-335

PACS: 87.58.Ji, 87.57.U-

\section{Introduction}

Electromagnetic waves energy emitted from a source is generally referred as radiation or EMR. Some expressions of it are light from the sun, heat radiation from an oven, and gamma rays from radioactive elements in soil. Besides of natural sources in the environment there are also artificial sources of radiation, mainly in medical and industrial appliances. We can distinguish two basic categories of radiation: ionizing and non-ionizing ones. Ionizing radiation carried by quanta of large energy can change the structure of irradiated matter, even hurting people causing chemical, biological changes in human body [1-6]. Non-ionizing radiation does not cause microscopic damage, but some types can cause chemical changes or get human body warm. X- and gammarays are tools for medical applications in diagnosis and therapy. Diagnostic techniques of nuclear medicine make benefit of radioactive tracers which emit gamma rays when administered within the body. These tracers are generally short-lived isotopes of chemical elements built into organic compounds involved in specific physiological processes. It allows body organs to be exactly scrutinised. Radioisotopes can be administered by injection, inhalation or orally. These tracers are known as radiopharmaceuticals in nuclear medicine.

\section{Material and method}

A radiopharmaceutical is a medication used in nuclear medicine that has a radioactive part and a pharmaceutical part. The mostly used radioactive isotope is Technetium-99m, applied in visualization of skeleton and heart muscle in particular. Other preparates, such as iodine 123, indium 111 and gallium 67 are also used.

*corresponding author; e-mail: umitkara@sdu.edu.tr
Fluorine 18 is a radioisotope used in positron emission tomography (PET) imaging [2,3]. It is the reason of high importance of radioactivity sources for nuclear medicine.

Drugs used in nuclear medicine, radiopharmaceuticals, are to be moved in special shielding containers called lead pigs or vial pigs. Lead as shielding material can be substituted by boron carbide. Parts of the container are made of composite of aluminum, copper and $\mathrm{B}_{4} \mathrm{C}$ powder. The grains of the aluminum, copper, and $\mathrm{B}_{4} \mathrm{C}$ were used in liquid-phase sintering method. An electrical furnace was made to fit into a mechanical press to conduct hot uni-axial pressing. First, mechanical alloying of the powders was tested in a $45 \mathrm{~mm}$ inner-diameter plastic container in a steel cylinder mixer for $1 \mathrm{~h}$ at $70 \mathrm{rpm}$. AlSi H13 grade hot work tool steel die with an inner square cross section was manufactured for the cold compaction and sintering of powders. After initial cold compacting of the powders under pressure of $50 \mathrm{MPa}$ sintering was carried out at $25 \mathrm{MPa}$ and $585^{\circ} \mathrm{C}$ for $10 \mathrm{~min}$ in inert nitrogen atmosphere. At the end of this manufacturing procedure pressure was released, the die (along with the specimen) was immediately taken out of the furnace and cooled in air.

\section{Results}

Data for this paper were gathered in Nuclear Medicine Department in Suleyman Demirel Research Hospital (Fig. 1). Effectiveness of a composite with boron carbide

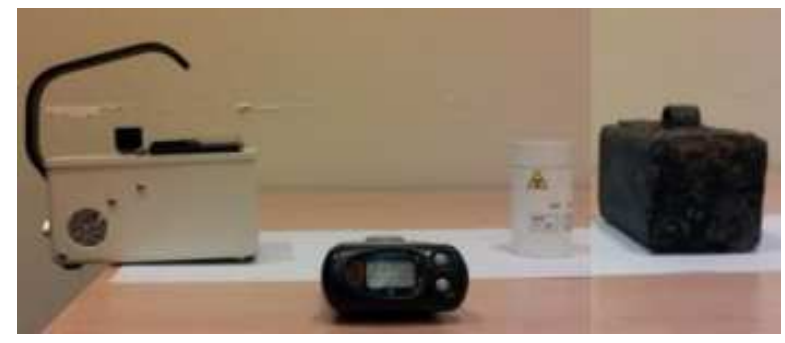

Fig. 1. Dosimeters and materials used in the experiment. 
as a material for vial pig in regard of radiation shielding has been tested. Efficiency of shielding was measured according to standard power law

$$
N_{d}=N_{0} \mathrm{e}^{-\mu d} \text {, }
$$

and half-value layer was obtained by

$$
H V L\left(X_{1 / 2}\right)=0.693 / \mu \text {. }
$$

In this study radiation shielding has been tested for $\mathrm{Tc}^{99 m}$, the most widely used radiopharmaceutical in nuclear medicine. The measurements of parameters crucial for radioactivity protection, i.e. irradiation dose and dose equivalent man rate has been performed using with Geiger-Müller counter and the Polimaster 1703MO-1b gamma spectroscopic dosimeter. The distance between the source and counter was varied.

\section{TABLE I}

HVL values for lead and water for radiation emitted from ${ }^{99 m} \mathrm{Tc}$ and ${ }^{131} \mathrm{I}$ commonly used in nuclear medicine.

\begin{tabular}{c|c|c}
\hline \hline nuclid & HVL lead, $[\mathrm{cm}]$ & HVL water, $[\mathrm{cm}]$ \\
\hline${ }^{99 m} \mathrm{Tc}$ & 0.025 & 0.97 \\
${ }^{131} \mathrm{I}$ & 0.22 & 6.24 \\
annihilation photon & 0.40 & 7.22
\end{tabular}

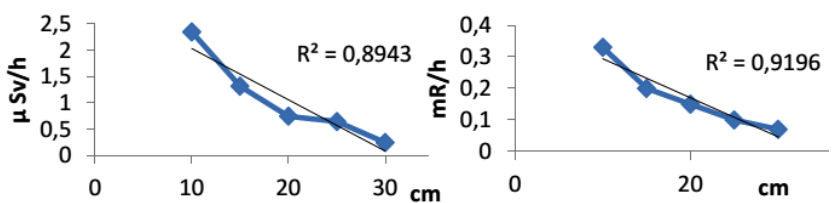

Fig. 2. The radiation doses without boron carbide shielding.

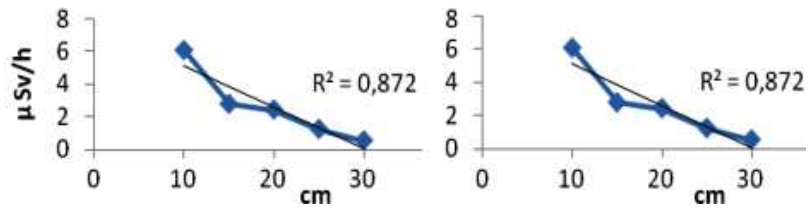

Fig. 3. The radiation doses with boron carbide shielding boron carbide radiation doses.

Results achieved in this study show that boron carbide composite is suitable shielding material for nuclear medicine appliances, mainly for containers for radiopharmaceuticals.

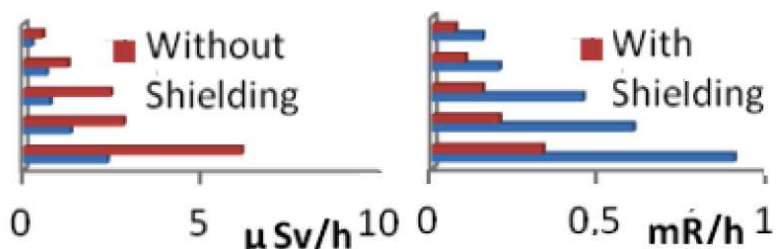

Fig. 4. The effectiveness of boron carbide shield.

TABLE II

Radiation doses at different distances with and without boron carbide shield

\begin{tabular}{c|c|c|c|c}
\hline \hline \multirow{2}{*}{$\begin{array}{c}\text { Distance } \\
{[\mathrm{cm}]}\end{array}$} & \multicolumn{2}{|c|}{ with shield } & \multicolumn{2}{c}{ without shield } \\
\cline { 2 - 5 } & {$[\mu \mathrm{SV} / \mathrm{h}]$} & {$[\mathrm{mR} / \mathrm{h}]$} & {$[\mu \mathrm{SV} / \mathrm{h}]$} & {$[\mathrm{mR} / \mathrm{h}]$} \\
\hline 10 & 6.1 & 0.9 & 2.35 & 0.33 \\
15 & 2.8 & 0.6 & 1.32 & 0.2 \\
20 & 2.45 & 0.45 & 0.75 & 0.15 \\
25 & 1.25 & 0.2 & 0.65 & 0.1 \\
30 & 0.55 & 0.15 & 0.25 & 0.07
\end{tabular}

\section{References}

[1] E.S. Amis Jr, P.F. Butler, K.E. Applegate, S.B. Birnbaum, L.F. Brateman, J.M. Hevezi, F.A. Mettler, R.L. Morin, M.J. Pentecost, G.G. Smith, K.J. Strauss, R.K. Zeman, J. Am. Coll. Radiol. 4, 272 (2007).

[2] The 2007 Recommendations of the International Commission on Radiological Protection, Ann. ICRP 37, 1 (2007).

[3] W. Huda, N.A. Gkanatsios, Health Phys. 75, 492 (1998).

[4] J. Kaneko, M. Katagiri, Y. Ikeda, T. Nishitani, in: Proc. 12 Workshop Radiation Detectors \& Their Uses, KEK, Tsukuba 1998, p. 98-4.

[5] M.H. Kharita, S. Yousef, M. AlNassara, Prog. Nucl. Energ. 50, 33 (2008).

[6] European Guidance on Estimating Population Doses from Medical Ray Procedures, Radiation Protection 154, European Commission, Luxembourg 2008. 